\title{
Cast Intermetallic Alloys and Composites Based on Them by Combined Centrifugal Casting-SHS Process
}

\author{
Vladimir Sanin*, Dmitry Andreev, Denis Ikornikov, Vldimir Yukhvid \\ Institute of Structural Macrokinetics and Materials Science RAS Chernogolovka, Moscow, Russia \\ Email: ${ }^{*}$ svn@ism.ac.ru
}

Received May 31, 2013; revised July 1, 2013; accepted July 10, 2013

Copyright (C) 2013 Vladimir Sanin et al. This is an open access article distributed under the Creative Commons Attribution License, which permits unrestricted use, distribution, and reproduction in any medium, provided the original work is properly cited.

\begin{abstract}
This work aims to establish a scientific and engineering background in the production of cast multicomponent alloys and metal-martix composite (MMCs) via Self-Propagating High Temperature Synthesis (SHS, combustion synthesis) which is a novel process technique regarding fast and low-cost production ability. We carried out the search for reactive systems and process parameters that would ensure preparation of cast multicomponent materials in a single process. The principles and methods of the SHS thermite-type reaction processes have been investigated under high-gravity values applying loads up to $1000 \mathrm{~g}$ with special centrifuge set-up. In this way we expected to improve the yield of target product, remove gaseous byproducts, diminish the grain size in the product, and make product composition more uniform. The obtained results can be expected to make a theoretical background for industrial-scale manufacturing of heat-resistant intermetallic alloys, master alloys, catalysts, MMCs etc.
\end{abstract}

Keywords: Metallothermic SHS; Cast Alloys; Intermetallic Alloys; MMC; Centrifugal Casting

\section{Introduction}

Intermetallic alloys (IAs) and metal-martix composites (MMCs) based on them are considered as most promising candidates in designing modern wear-resistant and high-strength materials. Due to attractive functional properties the intermetallic based materials are promising candidates for use in marine and aerospace propulsion engineering, power engineering, gas/oil transportation, as heavy-current electric contacts, structural engineering materials etc. [1-6].

One of the most widely used intermetallides is nickel, cobalt and titanium based. The materials based on the intermetallides have attracted great interests over the years for their use in wide range of applications starting from steel modifiers in extractive metallurgy to the advanced purposes such as special materials which are resistant to specific corrosion media and/or elevated operating temperatures even in high load, intense friction, and also abrasive conditions (e.g. as superalloys for gas-turbines, aviation engines, pressure vessels, heat-resisting alloys or as their coatings etc.). However homogeneous intermetallic materials exhibit low ductility at room temperature and inadequate yield strength at high tem-

${ }^{*}$ Corresponding author. peratures prevents them from wide industrial application. One of possible approach to increase the properties is forming heterogeneous intermetallic materials and MMCs by macro and micro alloying and incorporate metallurgicallly stable, hard and fine ceramic particles. In the case the best service parameters can be realized by uniform, regular, spatially ordered structure with controllable size/ shape of structural units [2-6] and a sufficiently high volume fraction of hard component. Another promising applicable field for intermetallic based materials is manufacturing multi-purpose catalysts $[7,8]$.

Currently, the main methods for the production of intermetallic alloys and the composites on them are classical vacuum furnace and/or powder metallurgy technologies. The classical furnace metallurgy uses metal oxides and their ores for the production of precursors for production such alloys. One of the main problems occurs especially when the specific weights of alloy and slag phases are close to each other since it results in a high level of impurity in alloys. Powder metallurgy uses, for example, expensive gas or water atomization etc. methods which also start with melting of these alloys in special furnaces prior to the following atomization stage. The common disadvantages for the commercial methods are high-energy consumptions, operating time, and the 
quantity/quality of suitable gas or vacuum needed along with the operation time.

One of energy and cost saving processing method for the synthesis of a wide variety of materials, including intermetallics, carbides, borides, silicides etc. is SelfPropagating High Temperature Synthesis (SHS) [9] frequently named as Combustion Synthesis. In the SHS process, after initiation, highly exothermic reaction becomes self-sustaining. The chemical conversion takes place in a combustion wave which moves over mixtures producing the desired product. Initial mixtures of metals and nonmetals (C, Si, B etc.) are used for SHS. To obtain cast materials in the combustion mode high exothermic initial mixtures of metal oxides, metal reducer and nonmetals are used. The approach combines two material production methods, namely an aluminothermic process [10] and SHS and is called as metallothermic SHS or SHS-metallurgy $[11,12]$. Since the adiabatic combustion temperatures $\left(T_{\mathrm{ad}}\right)$ of the SHS reactions obtained by the high energetic precursor mixtures change between 2500 and $3500 \mathrm{~K}$, the combustion products (alloy and oxide) are in liquid-phase state.

This work aims to establish a scientific and engineering background for high energy efficient, fast and lowcost production manufacturing technology. Some cast intermetallic alloys and MMC are based on via combined centrifugal casting - SHS. The authors have a more than 20 years' experience in the field.

\section{Experimental Procedure}

\subsection{Raw Materials and Processing Conditions}

The SHS reaction yielding cast materials based on intermetallic alloys can be represented in the form:

$$
\begin{gathered}
\left(O x_{1}+O x_{2}+O x_{3}+\ldots O x_{n}\right)+B_{k}+R+(F A) \rightarrow \\
\rightarrow \text { [polymetallicmaterial] }+R_{k} O_{l}+Q,
\end{gathered}
$$

where $O x_{i}$ - oxides of $\mathrm{Ni}, \mathrm{Co}, \mathrm{Ti}, \mathrm{Cr}, \mathrm{Nb}, \mathrm{Mo}, \mathrm{W}, \mathrm{V}, \mathrm{Mn}$ and so on, $\mathrm{B}_{\mathrm{k}}$-elements (B $\mathrm{C}, \mathrm{Si}, \mathrm{Zr}$, etc.), $R$-metal reducer (Al, Ti), FA-functianal additives $\left(\mathrm{CaO}_{2}, \mathrm{CaF}_{2}\right.$ etc.), [polymetallic material]-(intermetallic alloy and MMCs based on $\mathrm{Ni}, \mathrm{NiAl}_{3}, \mathrm{NiAl}, \mathrm{CoAl}$, TiAl etc.) $\mathrm{Q}-$ thermal effect of the process.

Figure 1 schematically illustrates the SHS process for fabrication of cast materials. After initiation with an igniting coil, the reaction frontally propagates downward. Because the attained temperatures (up to $3000^{\circ} \mathrm{C}$ ) are well above the m.p. of reaction products, the melt represents a mixture of mutually insoluble metallic (alloy) and oxide $\left(\mathrm{Al}_{2} \mathrm{O}_{3}\right)$ phases. Due to strongly different specific weights, these phases undergo gravity-assisted phase separation and subsequent crystallization. As the result the lower layer is polymetallic material (IAs, MMCs) while the upper one, $\mathrm{Al}_{2} \mathrm{O}_{3}$.

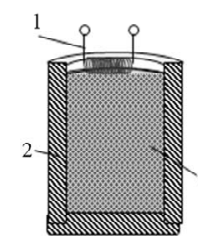

(a)

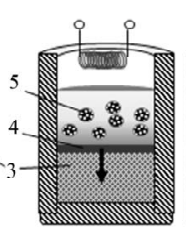

(b)

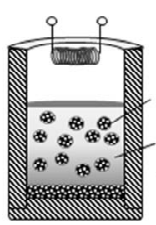

(c)

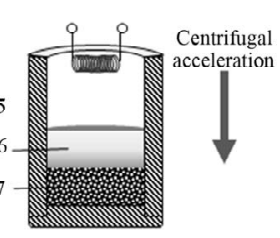

(d)
Figure 1. Schematic of the SHS process for fabrication of cast materials: (a) charge preparation, (b) combustion, (c) phase separation, (d) pattern formation. Here 1 stands for igniting coil; 2 , refractory mould; 3 , green composition; 4 , combustion front; 5 , polymetallic material globules in the melt; 6, oxide phase $\left(\mathrm{Al}_{2} \mathrm{O}_{3}\right)$; and 7 , cast polymetallic material (ingot).

Some characteristics of commercial powders used in our experiments are given in Table 1. Intermixing was performed in a TS-1 planetary mixer for $20 \mathrm{~min}$. The blends were then placed in cylindrical graphite containers (inner diameter 80 or $40 \mathrm{~mm}$ ) lined up with an alumina coating to minimize interaction with carbon. Burning velocity was determined in experiments with transparent silica containers.

As is known [13-16], the process can be made much more effective when carried out in conditions of high artificial gravity. In this way we can 1) improve the yield of target product, 2) remove gaseous byproducts, 3) diminish the grain size in the product, and 4) make product composition more uniform. Our present experiments were carried out using a centrifugal machine shown in Figure 2. Combustion was performed under normal pressure of atmospheric air at centrifugal acceleration $a=$ $10-500 \mathrm{~g}$. The assigned rotor (4) rotation velocity allows creation of the required overloads (centrifugal acceleration) from 1 to $1000 \mathrm{~g}$ during synthesis $(a / g=1-$ 1000 , where $a$ is a centrifugal acceleration, $g$ is a free fall acceleration). The changeable chambers were volume. Thus alloy ingots from green mixture from $0.1 \mathrm{~kg}$ up to 2 $\mathrm{kg}$ can be produced.

\subsection{Characterizations}

In our experiments, we measured the burning velocity $(U)$, material loss caused by sputtering $\left(\eta_{\text {sput }}\right)$, and the yield of target material $\left(\eta_{\text {ingot}}\right)$ using the following relationships:

$$
\begin{gathered}
U=h / t(\mathrm{~cm} / \mathrm{s}), h_{\text {sput }}=\left[\left(M_{0}-M\right) / M_{0}\right] \times 100(\%) \\
\mathrm{h}_{\text {ingot }}=\left(\mathrm{m} / \mathrm{m}_{\mathrm{c}}\right) \times 100(\%)
\end{gathered}
$$

where $h$ is the sample height, $t$ duration of combustion, $m$, $m_{\mathrm{c}}$ measured and estimated ingot weight, and $M_{0}$ and $M$ initial and final sample weight.

Combustion products were characterized by SEM/EDS (Zeiss Ultra plus microscope) and XRD (DRON-3 apparatus, $\mathrm{Cu}-K_{\alpha}$ radiation, $2 \theta=10^{\circ}-80^{\circ}$ ). Vickers hardness 


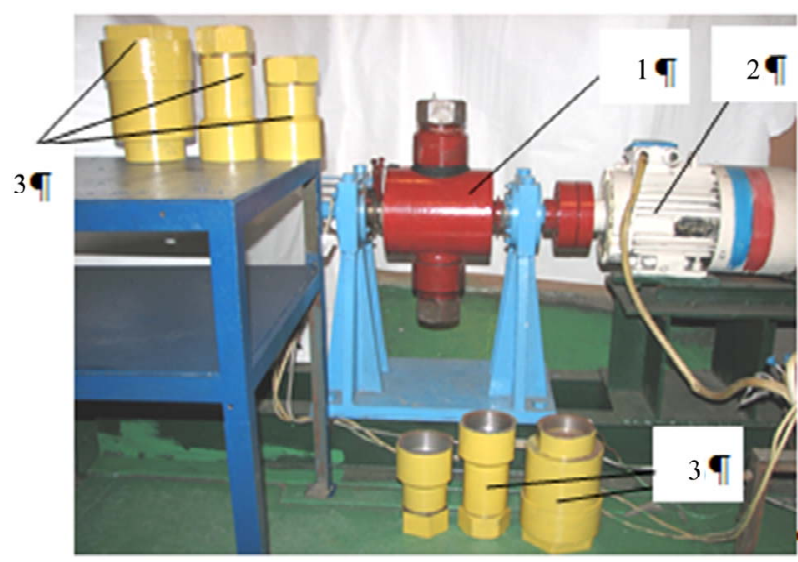

Figure 2. Overall view of a centrifugal SHS facility: (1) rotor; (2) electric motor, (3) changeable chamber with refractory mould.

Table 1. Reagents and alloying agents.

\begin{tabular}{ccc}
\hline & $\bar{d}, \mu \mathrm{m}$ & Purity, \% \\
\hline $\mathrm{NiO}$ & $<40$ & 99.0 \\
$\mathrm{MoO}_{3}$ & - & 99.4 \\
$\mathrm{Al}$ & $<50($ mostly $30-40)$ & 99.7 \\
$\mathrm{Cr}_{2} \mathrm{O}_{3}$ & $<20$ & 99.2 \\
$\mathrm{~V}_{2} \mathrm{O}_{5}$ & $<60$ & 99.6 \\
$\mathrm{MnO}_{2}$ & $<100$ & 99.7 \\
$\mathrm{Ti}$ & $<80$ & 99.8 \\
$\mathrm{~B}$ & $<1$ & 97.8 \\
$\mathrm{CaO}_{2}$ & $<10$ & 98.2 \\
$\mathrm{TiO}_{2}$ & $<50$ & 99.3 \\
\hline
\end{tabular}

$\left(H_{\mathrm{V}}\right)$ was measured using an HVS-50 testing machine. Prior to examination, metallographic specimens were etched in acid to remove matrix material.

\section{Results and Discussion}

\subsection{Synthesis of (Ni, Co, Mn) Alx Intermetallic Alloys}

Deep oxidation of $\mathrm{CO}$ and hydrocarbons as well as $\mathrm{NO}_{\mathrm{x}}$ reduction is the key problem in purification of exhaust gas from internal combustion engines and effluent gas flows from different industrial enterprises. To solve this problem, they now make use of systems for catalytic purification of exhaust gases whose main working element is a catalyst comprising noble metals such as $\mathrm{Pt}, \mathrm{Rh}$, and Pd. The limited resources of these metals and their high price in a constantly expanding consumer market motivate searches for new, more accessible materials with a high catalytic activity and stability. Highly porous multicomponent metallic catalysts (Raney metals or skeletal catalysts $[7,8]$ obtained from intermetallides of $3 d$ metals can serve as an alternative.

The main goal of the item our research to study the possibility of synthesizing multicomponent $46 \mathrm{Ni}-10 \mathrm{Co}-$ $3 \mathrm{Mn}-\mathrm{Al}$ (rest) and 56Ni-3Mn-Al (rest), wt $\%$ metallic materials based on using the SHS technique and subsequently processing them with the aim of using them as catalysts in the process of complete $\mathrm{CO}$ and hydrocarbons oxidation.

The general scheme of investigations consists of the following stages:

1) Study of the effect of synthesis conditions (ratio of source components, effect of overload, introduction of functional additions, etc.) on the combustion (synthesis) mode and formation of the phase composition and intermetallide structure.

2) Preparation of catalysts by grinding the synthesized intermetallide alloy and subsequent leaching of aluminum to obtain metallic materials with a branched surface.

3) Study of catalytic activity and stability of the obtained catalysts using a laboratory facility. On the basis of a comparative analysis of data on activity and stability of catalysts, the intermetallide composition was adjusted and the materials most promising for further investigations were revealed. The key emphasis in the work is placed on searching for optimal synthesis conditions.

For the investigation we selected three alloy composition. The general schemes of the chemical conversions for synthesis $(\mathrm{Ni}, \mathrm{Co}, \mathrm{Mn}) \mathrm{Al}_{\mathrm{x}}$ polymetallic alloys can be written as:

$$
\begin{aligned}
& 1-\mathrm{NiO}+\mathrm{Co}_{3} \mathrm{O}_{4}+\alpha \mathrm{Al} \\
& 2-\mathrm{NiO}+\mathrm{MnO}_{2}+\alpha \mathrm{Al} \\
& 3-\mathrm{NiO}+\mathrm{Co}_{3} \mathrm{O}_{4}+\mathrm{MnO}_{2}+\alpha \mathrm{Al}
\end{aligned}
$$

Preliminary experiments under normal gravity $(1 \mathrm{~g})$ with different ratios of aluminum concentrations showed that the compounds are capable of combustion in the SHS regime within a range at $\alpha>0.4$. With an increase in $\mathrm{Al}$ content in the source compound, the value of $v$ decreases, and at $\alpha>0.4$, combustion becomes impossible. In our case a high content of aluminum (over $45 \%$ ) is desirable since intense leaching and formation of a branched surface is possible just for such compounds.

The density of the metallic phase decreases with an increase in aluminum content in the source charge and in the produced alloy. In addition, the temperature of the reaction drops as well. This leads to deceleration of the phase separation and it does not have time to complete. The degree of separation $\left(\eta_{\mathrm{sp}}\right)$ (spread of products during combustion due to gasification of impurities and formation of lower oxides) of liquid metal and oxide phases after combustion under normal gravity is determined by a 
ratio of characteristic times of phase separation $\left(t_{s}\right)$ and cooling $\left(t_{c}\right)$ which is function of combustion temperature $\left(T_{c}\right)$ and gravity $(a=\mathrm{g})$.

$\eta_{s}$ $=A \frac{d_{m}^{2} a}{\alpha_{1} \mu_{0}} r \exp \left(-E_{v} / R T_{c}\right)\left[1-\exp \left(-E_{v}\left(T_{c}-T_{a r}\right) / R T_{c}^{2}\right)\right]$

Here $a$ is the centrifugal acceleration (under normal gravity $a=\mathrm{g}$ ), $T_{c}$ the combustion temperature, $T_{a r}$ the temperature at which the phase separation is arrested (the melting point of oxide phase), $d_{m}$ the diameter of the metal drop, $\alpha_{1}$ the heat transfer coefficient, $E_{v}$ the activetion energy of the viscosity, $\mu_{0}$ the pre-exponential factor of the viscosity, and $r$ the sample radius. So variation of $a$ is affective parameter for control of the synthesis process parameters.

Variations in the combustion velocity $(U)$ and mass losses $\left(\eta_{\mathrm{sp}}\right)$ depending on the aluminum content in the source compound is illustrated in Figure 3 by example of the $\mathrm{NiO}+\mathrm{MnO}_{2}+\alpha \mathrm{Al}$ mixture under g-condition $400 \mathrm{~g}$. So overloads higher than $400 \mathrm{~g}$ allow expansion of the combustion interval up to $\boldsymbol{\alpha}>0.6$ and obtainment of ingots with a high content of Al. Thus source compositions were combusted under the effect of centrifugal forces ( $\boldsymbol{a}$ $=500 \mathrm{~g})$.

Formation of sample macrostructure depends significantly on completeness of the phase separation. As a rule, at low overloads (less than $100 \mathrm{~g}$ ), a sintered composition with a cermet structure is formed; here, the matrix is formed by an oxide phase where metallic drops are uniformly distributed. Overloads higher than $400 \mathrm{~g}$ allow two-layer products with a close-cut separation of layers to be obtained where the lower layer is an ingot of the desired metallic alloy and the upper layer mainly consists of aluminum oxide (corundum). When phase separation is complete, the lower metallic layer is easily separated from the upper one after a slight mechanical action.

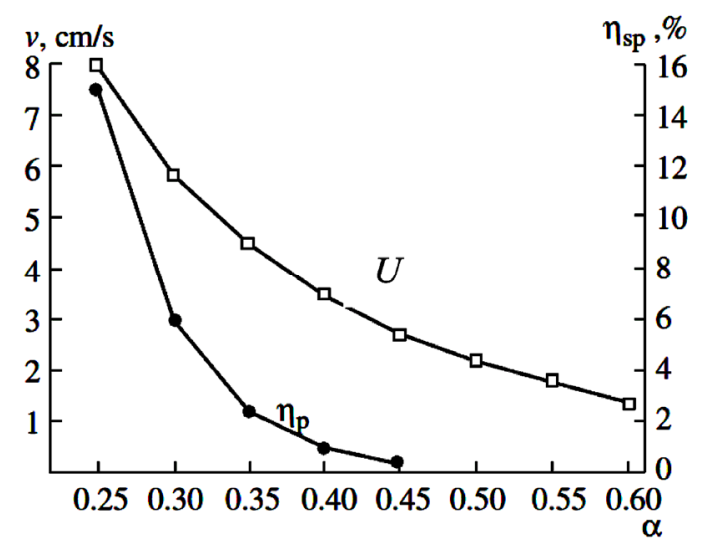

Figure 3. Dependences of combustion velocity $(U)$ and spread depth $\left(\eta_{\mathrm{sp}}\right)$ on $\mathrm{Al}$ content in $\mathrm{NiO}+\mathrm{MnO}_{2}+\alpha \mathrm{Al}$ source mixture (under $400 \mathrm{~g}$ ).
A study of intermetallide sample surface sections with an electron microscope (Figures 4 and 5) revealed several intermetallide phases. On microphotos magnified up to 1000 times (Figures 4(a), (b) and 5(a), (b)), it is seen that the volumetric distribution of structural components is fairly uniform and does not have local nonuniformities. The XRD analysis of the Ni-Mn-Al intermetallide revealed five main phases, namely, $\mathrm{NiAl}_{3}, \mathrm{Ni}_{2} \mathrm{Al}_{3}, \mathrm{Mn}_{4} \mathrm{Al}_{11}$, $\mathrm{Mn}_{5} \mathrm{Al}_{8}$, and $\mathrm{Mn}_{6} \mathrm{Al}$; for $\mathrm{Ni}-\mathrm{Co}-\mathrm{Mn}-\mathrm{Al}$, a $\mathrm{CoAl}_{3}$ phase is observed in addition to the above-mentioned phases. A microanalysis of the sample surface (Figures 4(c) and 5(c)) showed that the phases of manganese aluminides are mainly concentrated in the dark gray regions, i.e., at the boundaries of the grains which consist of nickel and cobalt aluminides (light gray and gray regions).

The data obtained with scanning electron microscopy show that the entire surface of leached samples is covered with a thin film of $d$-metal oxides, but their presence in the samples is not confirmed by the roentgen-phase analysis. The total concentration of oxides is likely to be less than $5 \mathrm{wt} \%$, which is lower than the sensitivity threshold of the roentgen-phase analysis. The catalyst surface begins oxidizing in the process of leaching and finishes in the air during drying. Figure 6 shows the microstructure of surface sections under different magnifycation for Ni-Co-Mn catalysts. Their surface geometry is highly eroded. On some sample sections, we can easily see a thick layer of nanosized fibers $1-2 \mu \mathrm{m}$ long and $80-90$ $\mathrm{nm}$ thick. However, the formation of this structure
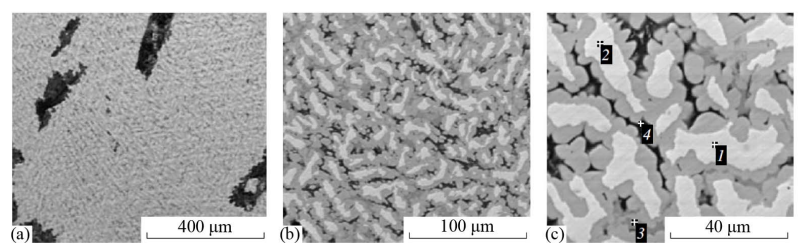

Figure 4. Microstructure of Ni-Mn-Al intermetallides: Spectrum. (1) 40.41 Al, 0.32 Mn, $59.72 \mathrm{Ni}$; (2) 40.86 Al, 0.28 Mn, 58.85 Ni; (3) 62.56 Al, 22.62 Mn, $14.83 \mathrm{Ni}$; (4) 90.41 Al, 1.73 Mn, 7.87 wt\% Ni.

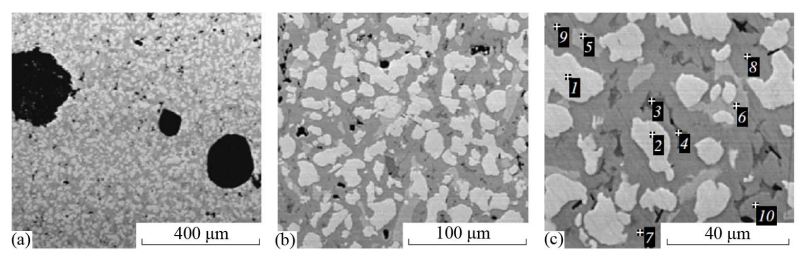

Figure 5. Microstructure of Ni-Co-Mn-Al intermetallides: Spectrum. (1) 04 Al, 4.53 Co, 54.43 Ni; (2) 40.87 Al, 5.14 Co, 53.98 Ni; (3) 61.95 Al, 22.44 Mn, 2.15 Co, 13.47 Ni; (4) 62.15 Al, 21.94 Mn, 1.73 Co, 14.18 Ni; (5) 50.26 Al, 1.12 Mn, 10.76 Co, 37.86 Ni; (6) 51.37 Al, 1.20 Mn, 11.15 Co, 36.28 Ni; (7) 55.23 Al, 3.98 Mn, 4.42 Co, $36.36 \mathrm{Ni}$; (8) $56.38 \mathrm{Al}, 0.41 \mathrm{Mn}$, 3.85 Co, 39.36 Ni; (9) $56.42 \mathrm{Al}, 1.19 \mathrm{Mn}, 3.21 \mathrm{Co}, 39.18 \mathrm{Ni}$; (10) $55.53 \mathrm{Al}, 0.28 \mathrm{Mn}, 3.75 \mathrm{Co}, 40.44 \mathrm{wt} \% \mathrm{Ni}$. 

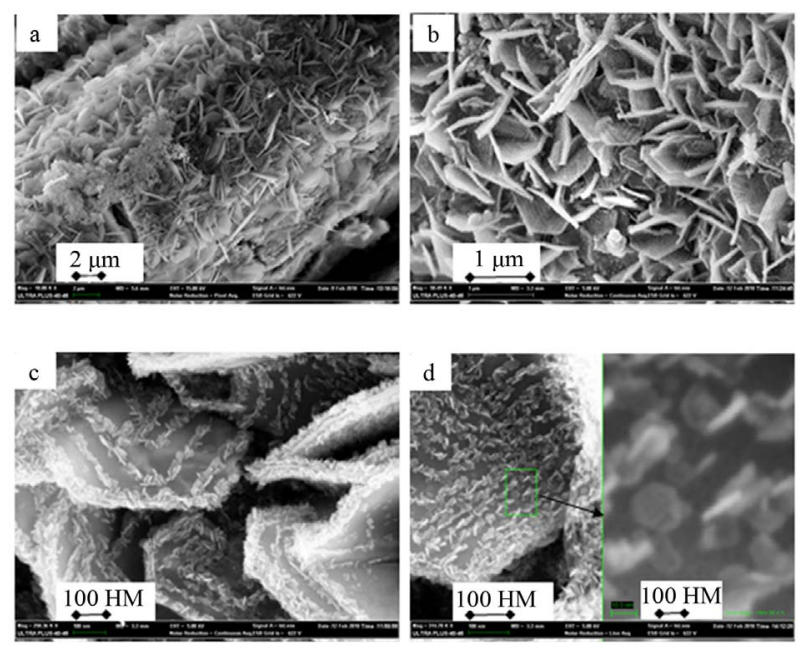

Figure 6. Microstructure of the surface of Ni-Co-Mn-Al catalysts ((a)-(d) is micro photo under different magnification).

does not yield a significant increase in the specific surface of the catalysts owing to its relatively small portion in the material volume. A microanalysis of such sections showed that the content of oxygen in this layer is significant. These nanofibers seem to be oxide or metal oxide formations.

The studies of the obtained catalysts showed that the samples under analysis are characterized by high catalytic activity. The samples of $\mathrm{Ni}-\mathrm{Co}$ catalysts obtained at the initial stage are highly active, but their stability is far from satisfactory [17]. An addition of manganese yielded a significant improvement of the results concerning all parameters. In the Ni-Mn-Al system, the temperature of a $100 \%$ conversion of $\mathrm{CO}$ is $175^{\circ} \mathrm{C}$ for the most active catalyst sample. For propane, a $90 \%$ conversion is achieved at $250^{\circ} \mathrm{C}$. The Ni-Co-Mn-Al catalyst demonstrated better results as far as its activity and stability are concerned. With an increase in the Mn content in the source intermetallide, its structure becomes even more complex; as a result, after leaching, the active surface of the catalyst covered with nanosized fibers increases. However, the specific surface of these samples varies only slightly.

\subsection{Synthesis of Ni-Cr-Al-Si-C and Co-V-Al-Si-C Multi-Component Master Alloys}

Master alloys are used worldwide. Invariably they are found in plants where metal is melted, alloyed with various elements and then cast into shapes. This can be aluminium, superalloys, steels and even precious metals.

One of the main applications is composition adjustment, i.e. changing the composition of the liquid metal to achieve the desired chemical specification. Another im- portant application is structure control-influencing the microstructure of a metal during casting and solidification in order to change its properties. Owing to the alloying metallic materials acquire a complex of properties such as: high strength, corrosion resistance, wear resistance under high temperatures, loads and intense friction. These properties have multi-component alloys (superalloys) based on $\mathrm{Ni}, \mathrm{Co}$ and $\mathrm{Fe}$ of which produce the most loaded items of machinery, for example items of the power setups of gas turbine type.

Reasons for using a master alloy instead of a pure metal can be economical, technical or both. Some elements show high losses or poor yield when added in pure form. Others will not dissolve at all at the furnace temperature prevailing in a casthouse. A master alloy often provides the solution, as it dissolves much quicker at lower temperatures, saving valuable energy and production time. Now most often for production of the superalloys are used bicomponent master alloys (ingots, balls, etc.). The complexity and high energy consumption of the technologies define high cost of such alloys and scale down of their application.

The application of multi-component master alloys in metallurgy of the alloys can promote a decline a operation time of vacuum furnace and simplify exist comercial technology. So, the item of the work focused on explores the feasibility of obtaining cast multi-component master alloys by SHS. Below for instance of Ni-Cr-Al-Si and Co-V-Al-Si system it will be demonstrated.

The basic chemical reactions for synthesis of the selected systems are follow:

$$
\begin{aligned}
& \mathrm{a} \mathrm{NiO}+\mathrm{b} \mathrm{Cr}_{2} \mathrm{O}_{3}+\mathrm{c} \mathrm{Al}+\mathrm{d} \mathrm{Si}=> \\
& =>[\mathrm{Ni}-\mathrm{Cr}-\mathrm{Al}-\mathrm{Si}]+\alpha \mathrm{Al}_{2} \mathrm{O}_{3} \text {, } \\
& \text { a } \mathrm{Co}_{3} \mathrm{O}_{4}+\mathrm{b} \mathrm{V} \mathrm{V}_{5}+\mathrm{c} \mathrm{Al}+\mathrm{d} \mathrm{Si}=> \\
& =>[\mathrm{Co}-\mathrm{V}-\mathrm{Al}-\mathrm{Si}]+\alpha \mathrm{Al}_{2} \mathrm{O}_{3} \text {, }
\end{aligned}
$$

A thermodynamic analysis (Figure 7) revealed that the range of the combustion temperatures that could happen at variation of the ratio of initial mixtures is high. All component of the alloys are in melt stage. Realization such high temperature in combustion wave makes it possible to obtain cast alloys.

For both system under study, comparative the microstructure alloys obtained with the different values of the overload (up to $1000 \mathrm{~g}$ ) realized by centrifuge and under normal gravity (1 g) showed that chemical composition and microstructure formation dependent of gravity during combustion (Figures 8(a), (b) and 9(a), (b)). The action of gravity is observed depth of chemical conversion for V, Si and Cr. Most effect is observed for Si content. High gravity leads to increase of Si content. Samples obtained under $1 \mathrm{~g}$ include oxide phase bubbles $\left(\mathrm{Al}_{2} \mathrm{O}_{3}\right)$. Across samples obtained under $\mathrm{g}>500$ consist 


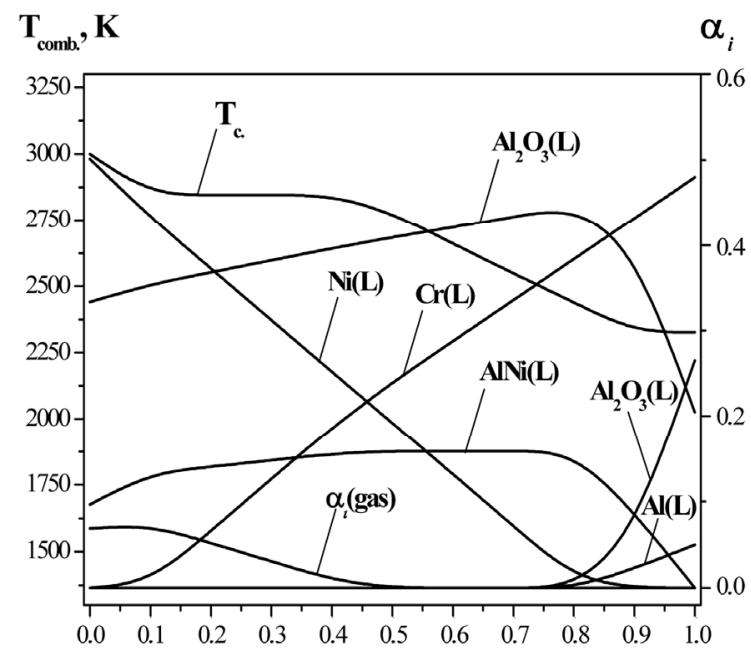

(a)

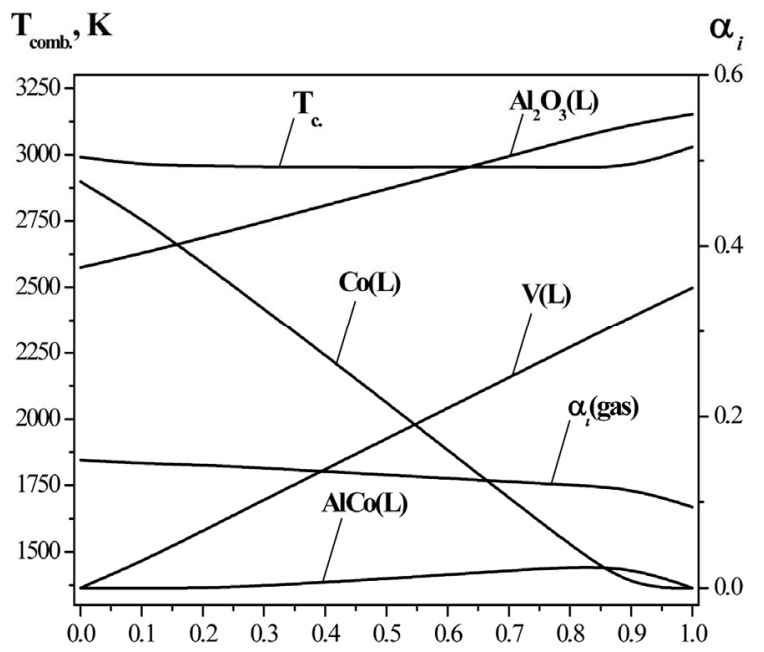

(b)

Figure 7. The results of thermodynamic analysis of adiabatic temperature and values possible product composition change at variation of the ratio of initial mixture. (a) $x$ $(3 \mathrm{NiO}+2 \mathrm{Al}), \mathrm{y}\left(\mathrm{Cr}_{2} \mathrm{O}_{3}+2 \mathrm{Al}\right)+5 \mathrm{wt} \% \mathrm{Al}, \mathrm{a} \mathrm{NiO}+\mathrm{b} \mathrm{Cr}_{2} \mathrm{O}_{3}$ $+\mathrm{c} \mathrm{Al}+\mathrm{d} \mathrm{Si}$; (b) x $\left(3 \mathrm{Co}_{3} \mathrm{O}_{4}+8 \mathrm{Al}\right), \mathrm{y}\left(3 \mathrm{~V}_{2} \mathrm{O}_{5}+10 \mathrm{Al}\right)+5$ wt.\% Al, a $\mathrm{Co}_{3} \mathrm{O}_{4}+\mathrm{b} \mathrm{V} \mathrm{V}_{2} \mathrm{O}_{5}+\mathrm{c} \mathrm{Al}+\mathrm{d} \mathrm{Si}$.

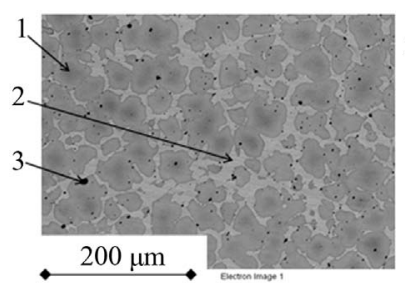

(a)

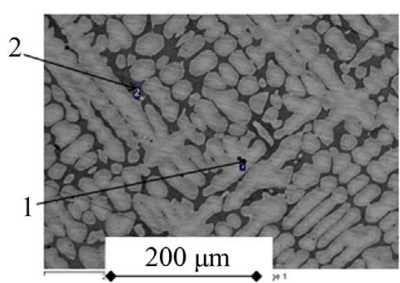

(b)
Figure 8. Microstructure of Co-V-Al-Si alloy. (a) Synthesized under normal gravity (1 g) and (b) under high gravity (1000 g). Spectrum (for sample a): (1) $72.89 \mathrm{Co}, 11.10 \mathrm{~V}$, 10.84 Al, 1.17 Si; (2) 82.34 Co, 11.94 V, 4.23 Al, 1.50 Si; (3) $1.20 \mathrm{Co}, 51.18 \mathrm{Al}, 47.6 \mathrm{wt} \%$ O. Spectrum (for sample b): (1) 83.39 Co, 10.50 V, 1.31 Al, 4.81 Si; (2) 72.48 Co, 13.89 V, 1.73 Al, 9.90 Si.

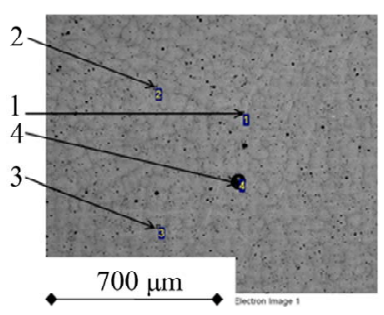

(a)

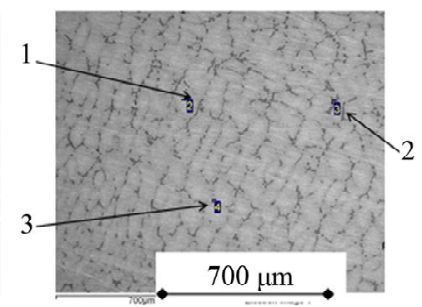

(b)
Figure 9. Microstructure of Ni-Cr-Al-Si alloy. (a) Synthesized under normal gravity (1 g) and (b) under high gravity (1000 g). Spectrum (for sample a): (1) $74.40 \mathrm{Ni}, 18.08 \mathrm{Cr}$, 7.53 Al, 1.17 Si; (2) 73.20 Ni, 17.76 Cr, 8.51 Al, 0.52 Si; (3) 74.72 Ni, 16.28 Cr, 8.59 Al, 0.41 Si; (4) 0.40 Ni, 44.06 Al, 54.19 wt \% O. Spectrum (for sample b): (1) $77.42 \mathrm{Ni}, 13.65$ Cr, 8.11 Al, 0.83 Si; (2) 71.90 Ni, 10.49 Cr, 14.34 Al, 3.27 Si; (3) $75.27 \mathrm{Ni}, 14.28 \mathrm{Cr}, 7.99 \mathrm{Al}, 2.47 \mathrm{Si}$.

of target component only. So effect of gravity increase product capacity and it quality.

\subsection{Synthesis of Ti-Al and Ti-Al-Nb Intermetallic Alloys}

Gamma-Titanium Aluminides, have desirable mechanical and physical attributes at temperatures up to $800^{\circ} \mathrm{C}$. With properties that include a high melting point, high strength, minimal creep and low density, they are ideal candidates for high-performance gas turbine blades.

Using titanium aluminide would result in a $50 \%$ weight reduction of turbine components compared to current $\mathrm{Ni}$ based alloys, leading to improved thrust-to-weight ratios of aero-engines, higher efficiency, reduced fuel consumption and lower exhaust emissions. However, advances in the development of TiAl alloys $[18,19]$ are held back by the lack of a successful process for their manufacture at an appropriate quality and acceptable cost. Existing processes for fabrication of titanium aluminides are multistage and time-consuming. In this context, elaboration of new cost-effective methods or simplification of existing ones seems to be of current importance.

The item of the work focused on explores the feasibility of preparing Ti-50Ala and $\mathrm{Ti}-46 \mathrm{Al}-8 \mathrm{Nb}$ (indicated are at.\%) ingots as precursors for following treatment by vacuum arc melting (VAM).

The general schemes of the chemical conversions during Ti-Al and Ti-Al-Nb intermetallic alloys synthesis can be written as

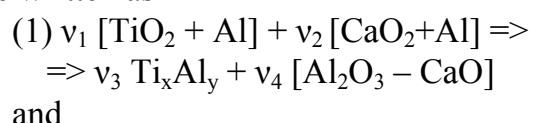

$$
\text { (2) } \begin{aligned}
& v_{1}\left[\mathrm{TiO}_{2}+\mathrm{Nb}_{2} \mathrm{O}_{5}+\mathrm{Al}\right]+v_{2}\left[\mathrm{CaO}_{2}+\mathrm{Al}\right]=> \\
= & >v_{3} \mathrm{Ti}_{\mathrm{x}} \mathrm{Nb}_{\mathrm{y}} \mathrm{Al}_{\mathrm{z}}+v_{4}\left[\mathrm{Al}_{2} \mathrm{O}_{3}-\mathrm{CaO}\right]
\end{aligned}
$$

A prerequisite for SHS casting materials is that the attained combustion temperature $T_{\mathrm{c}}$ must be higher than the melting point $T_{\mathrm{m}}$ of combustion products: $T_{\mathrm{c}}>T_{\mathrm{m}}$. 
The data of thermodynamic calculations (Figure 10) show that the $T_{\text {ad }}$ values for the both selected product forming mixtures are insufficient for the purpose: $T_{\mathrm{ad}} \leq$ $T_{\mathrm{m}}$. In the presence of unavoidable heat losses, the real $T_{\mathrm{c}}$ values are still lower. To obtain cast alloys in the mode of autowave synthesis, the burning temperature must be increased. Apart from that, the "power" admixture introduced into the targeted mix-of its reaction must not take part in formation of the alloy compound and must have high exothermicity. Thermodynamic analysis of many systems has shown that, for these requirements, the reaction of alumothermal reduction of calcium peroxide is optimal:

$$
\mathrm{CaO}_{2}+\mathrm{Al}->\mathrm{Al}_{2} \mathrm{O}_{3}-\mathrm{CaO} \text {. }
$$

Upon admission of the energy-producing mixture $\mathrm{CaO}_{2}-\mathrm{Al}$ into our systems, $T_{\text {ad }}$, markedly grows (Figure 10), which opens up a route to producing cast aluminides in the mode of combustion. For $v_{2}>0.2$, all the products can be expected to appear in the form of melt. In addition, the selected mixture yields the products which are inert toward the target products. With increasing $T_{\mathrm{c}}$, the amount of gaseous products (suboxides, Al vapor) can increase, which may lead to melt splashing. As a result, an optimum for $v_{2}$ can be expected to happen in the range $0.2-0.4$

With increasing $v_{2}$, the splash of melted material becomes more and more probable. In preliminary experiments under normal conditions $\left[P=0.1 \mathrm{MPa}\right.$ (air), $T_{0}=$ $293 \mathrm{~K}, a=1 \mathrm{~g}$ ], we determined the optimal values of $v_{2}$ for each product-forming mixture. Within these ranges of the relative amount of energy-producing component $v_{2}$ ( 0.3 - 0.45), dense titanium aluminides could be prepared in a high yield (good separation of phases). The outward appearance of the samples burned at different $a$ is shown in Figure 11. It follows that the extent of phase separation grows with increasing $a$. The samples obtained at $a$ $=300-1000 \mathrm{~g}$ represented a cylindrical ingot with the readily separated metallic and oxide layers.

Cast titanium aluminides can be readily prepared within

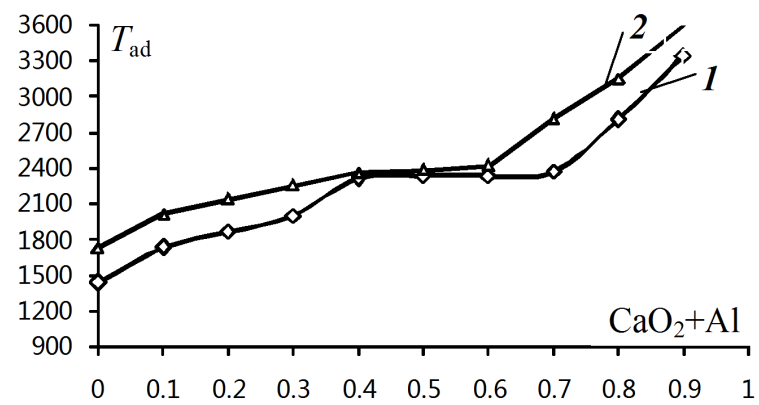

Figure 10. Calculated $\boldsymbol{T}_{\text {ad }}$ vs. the relative amount of energyproducing component $\left(v_{2}\right)$. 1 Calculated alloy composition (at.\%) Ti-Al(50); 2 Calculated alloy composition (at.\%) Ti$\mathrm{Al}(46)-\mathrm{Nb}(8)$.

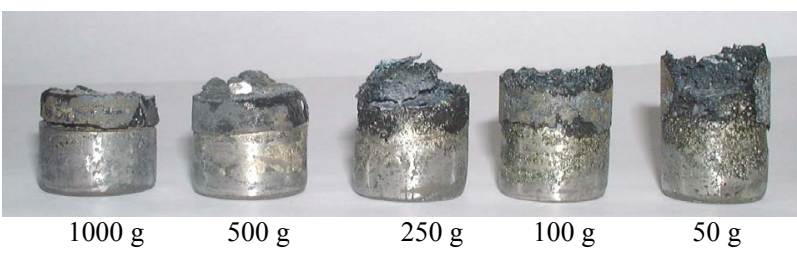

Figure 11. Effect of $a$ on the macrostructure of products (outward appearance after extraction from mould).

the range of optimal $v_{2}$. Varying the relative amount of components in the product-forming mixture, we can change the chemical composition of ingots and thus come to the target composition (atom \%) Ti-Al(46)- $\mathrm{Nb}(8)$.

The synthesized ingots were examined with analytical chemical tests and SEM. It was found that rising overload lead to increase of $\mathrm{Ti}$ and $\mathrm{Nb}$ content in the ingots (Table 2).

This influence explains by the fact that under the action of gravity the densification of reaction zone occurs [9]. Growth of the completeness of chemical interaction in the redox reactions of titanium $\left(\mathrm{TiO}_{2}+\mathrm{Al}\right)$ and the oxide of niobium $\left(\mathrm{Nb}_{2} \mathrm{O}_{5}\right)$ leads to increasing in their content in the ingots. Calculation of the influence of the completeness of the output of the purposeful elements from the value of gravity allowed obtaining ingots with the required composition.

Despite the fact that the synthesis was carried out to the atmosphere of air of the noticeable isolations of nitrogen it is not discovered. This indicates, but that, that the forming oxide (slag) layer as a result of the phase separation on it ensured the protection of products from the oxidation to the surface of metallic fusion in air and the possible nitration of titanium.

According to XRD data, no Nb-containing intermetallics were detected, despite a high $\mathrm{Nb}$ content. The obtained diffraction patterns (Figure 12) exhibit the presence of $\gamma^{\prime}-\mathrm{TiAl}$ and $\alpha_{2}-\mathrm{Ti}_{3} \mathrm{Al}$. All the peaks are shifted toward greater interplanar distances, which can be associated with formation of a solid solution of $\mathrm{Ni}$ in the TiAl lattice. According to the literature data, the solubility of $\mathrm{Nb}$ in TiAl attains a value of 11 at.\% (in our case, 8 at.\%).

No nitrogen-containing products were detected, which can be attributed to the protection of the melt from nitridation with atmospheric nitrogen by the slag layer formed on the melt surface.

The above data confirmed the prediction of thermodynamic calculations about the inertness of the products formed upon combustion in the $\mathrm{CaO}_{2}+\mathrm{Al}$ system towards the melt. The aluminides contained no Ca-containing products even for relative amount of energyproducing component $v_{2}>50 \%$.

Comparative studies the microstructure of the ingots of those obtained with the different values of the overload 


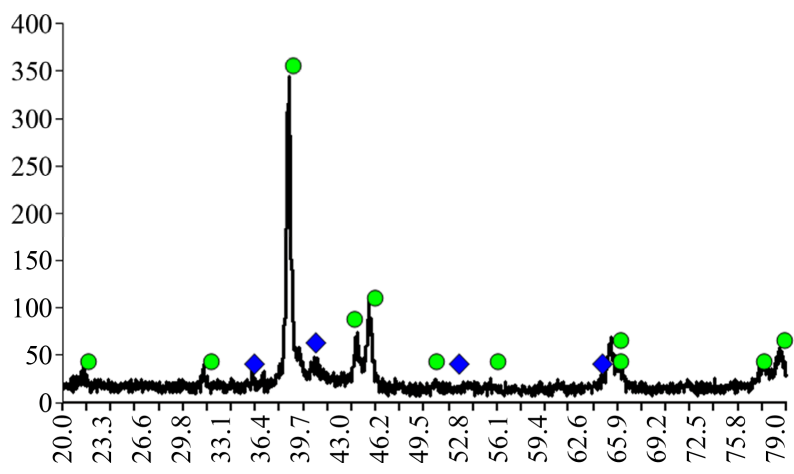

Figure 12. Typical diffraction patterns for SHS-produced $\mathrm{Ti}_{3} \mathrm{Al}$ and $(\mathrm{O}) \mathrm{TiAl}$.

Table 2. Chemical composition of ingots obtained at different a.

\begin{tabular}{cccccc}
\hline \multirow{2}{*}{$\begin{array}{c}\text { Target composition } \\
\text { (at.\%) }\end{array}$} & Elements & \multicolumn{4}{c}{ Composition (at.\%) } \\
\cline { 3 - 6 } & & $50 \mathrm{~g}$ & $250 \mathrm{~g}$ & $500 \mathrm{~g}$ & $1000 \mathrm{~g}$ \\
\hline & $\mathrm{Ti}$ & 48.77 & 47.84 & 45.8 & 45.93 \\
$\mathrm{Ti}-8$ & $\mathrm{Nb}$ & 7.91 & 7.96 & 8.21 & 8.43 \\
$\mathrm{Al}-46$ & $\mathrm{Al}$ & 42.74 & 43.02 & 45.81 & 45.95 \\
$\mathrm{Nb}-8$ & Others (B,C) & 0.28 & 0.71 & 0.78 & 0.16 \\
\hline
\end{tabular}

revealed that grain size decrease with growth g-forces. The action of gravity is observed reduction in the heterogeneity and under the influence of gravity an alloy has most homogenous structure. The alloys obtained under $300-400 \mathrm{~g}$ has high heterogeneity in composition (liquation) Figure 13.

\subsection{Synthesis of Cast $\mathrm{Mo}_{2} \mathrm{NiB}_{2}$ and $\mathrm{Mo}_{2} \mathrm{FeB}_{2}$ Metal-Matrix Composites (MMCs)}

Systematic theoretical and experimental studies on MoNi-B, Mo-Fe-B, W-Ni-B, W-Co-B, etc. phase diagrams have shown [20-30] that the complex borides $\mathrm{Mo}_{2} \mathrm{NiB}_{2}$, $\mathrm{Mo}_{2} \mathrm{FeB}_{2}, \mathrm{~W}_{2} \mathrm{NiB}_{2}$, and MoCoB may come in thermodynamic equilibrium with a metal matrix of $\mathrm{Ni}, \mathrm{Fe}$ or $\mathrm{Co}$. This gives hopes for preparation of stable MMCs in the form of a ductile metal matrix containing uniformly distributed particles of hard and refractory transitionmetal borides. Such MMCs have been found to show a unique combination of properties: high strength and excellent corrosion resistance in conditions of heavy loading and friction at high temperatures. Nevertheless, these materials have not yet found their wide application largely because of complicated technology for their production. Their high melting point is an obstacle for using conventional metallurgical processes. These materials are normally fabricated by the methods of powder metallurgy, hot isostatic pressing, reactive sintering, spark sintering, etc. $[20,22,24-28,30]$ whose drawbacks are high energy requirements, complexity, and expensive equipment.

In this part of the work, we attempted to fabricate cast

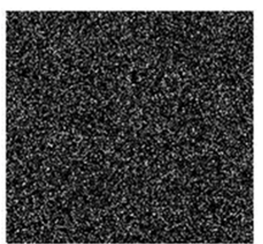

TiKa1

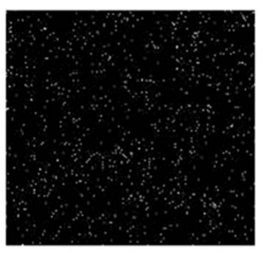

OKa1

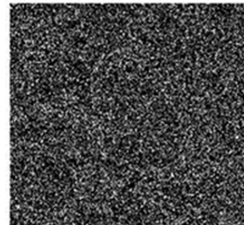

AlKa1

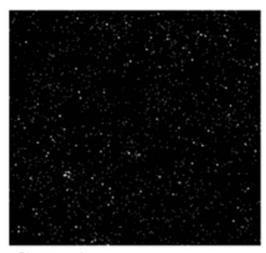

CaKal

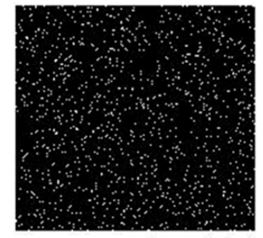

NbKal

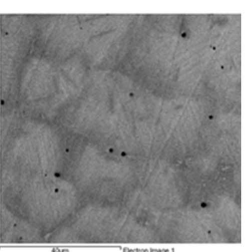

SEM picture
Figure 13. Distribution of elements and the results EDS from the surface of ingot. Calculated alloy composition (at.\%) Ti-Al(46)-Nb(8). Summary Spectrum: 45.99 Al; 45.64 Ti; 8.27 Nb; 0.01 Ca.

MMCs containing $\mathrm{Mo}_{2} \mathrm{NiB}_{2}$ and $\mathrm{Mo}_{2} \mathrm{FeB}_{2}$ by combined centrifugal casting - SHS process. This research aimed at investigation for reactive systems and process parameters that would ensure simultaneous preparation of both metal matrix and boride filler in a single process. The SHS reaction yielding cast MMCs based on $\mathrm{Mo}_{2} \mathrm{NiB}_{2}$ and $\mathrm{Mo}_{2} \mathrm{FeB}_{2}$ can be represented in the form:

$$
\begin{aligned}
& \mathrm{MoO}_{3}+\mathrm{NiO}\left(\mathrm{Fe}_{2} \mathrm{O}_{3}\right)+\mathrm{Al}+\mathrm{B}+(\mathbf{A A}) \\
& \rightarrow \mathrm{MMC}+\mathrm{Al}_{2} \mathrm{O}_{3}+Q
\end{aligned}
$$

where $\mathrm{MMC}=\mathrm{Mo}_{2} \mathrm{NiB}_{2}-\alpha \mathrm{Ni}$ or $\mathrm{Mo}_{2} \mathrm{FeB}_{2}-\beta \mathrm{Fe}$, alloying agent $\mathbf{A A}=\mathrm{Cr}_{2} \mathrm{O}_{3}, \mathrm{~V}_{2} \mathrm{O}_{5}, \mathrm{MnO}_{2}$, etc., and $\alpha, \beta$ stand for respective mass fractions.

\subsubsection{Combustion and Phase Segregation}

As showed by preliminary experiments the complex borides $\mathrm{Mo}_{2} \mathrm{NiB}_{2}$ and $\mathrm{Mo}_{2} \mathrm{FeB}_{2}$ can be obtained within a wide range of parameters $\alpha$ and $\beta$ (roughly characterizing the mass fraction of matrix material). Thus prepared MMCs exhibited no residual porosity, that is, had a character of cast materials, with a small contraction cav- ity at the center. An increase in $\alpha$ and $\beta$ was found to have only slight influence on $U$ : it increased from 4 to $5 \mathrm{~cm} / \mathrm{s}$.

It is well known that complete melting of system components is a prerequisite for good sensitivity of the process to gravity forces [13-16,31]. Figure 14 shows the burning velocity $(U)$, material loss $\left(\eta_{\text {sput }}\right)$, and product yield $\left(\eta_{\text {ingot }}\right)$ as a function of $a / \mathrm{g}$. The $U$ values are seen to grow with increasing $a / \mathrm{g}$. The effect is most pronounced within the range of $a=1-100 \mathrm{~g}$.

Strong influence of mass forces on burning velocity was associated [13-16] with intensification of convection and deformation within the reaction zone, which improves the completeness of combustion reaction. An in- 


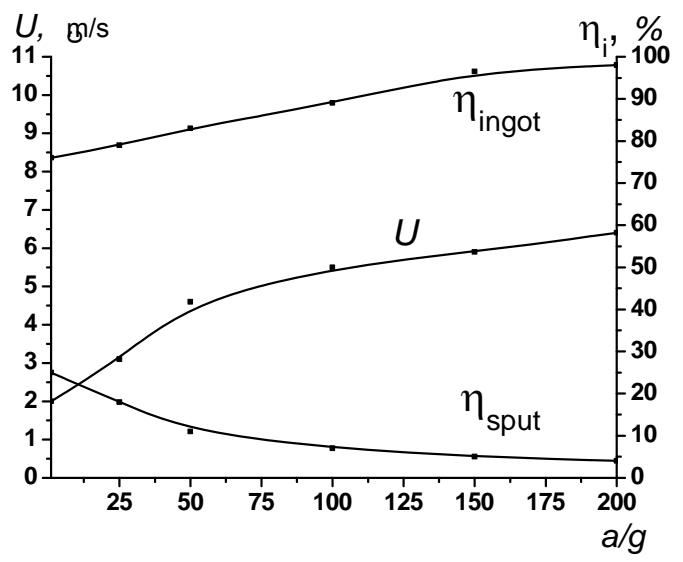

(a)

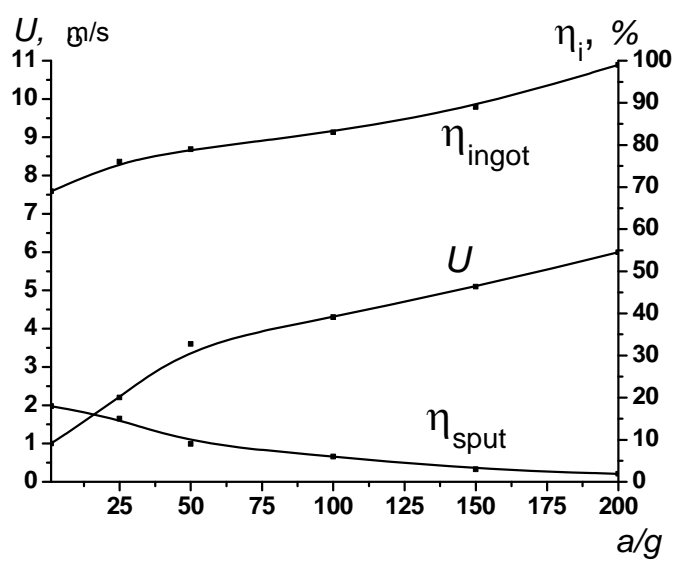

(b)

Figure 14. Burning velocity $(U)$, material loss $\left(\eta_{\text {sput }}\right)$, and product yield ( $\eta_{\text {ingot }}$ ) as a function of $a / g$ for $\mathrm{Mo}_{2} \mathrm{NiB}_{2}-\mathbf{0 . 2 1}$ $\mathrm{Ni}$ (a) and $\mathrm{Mo}_{2} \mathrm{FeB}_{2}-\mathrm{0.35Fe}$ (b) composites.

crease in $a / g$ is also accompanied by a decrease in material loss $\left(\eta_{\text {sput }}\right)$ and an increase in the yield of target product $\left(\eta_{\text {ingot }}\right)$. Above $150 \mathrm{~g}$, the $\eta_{\text {ingot }}$ values get close to theoretical ones.

All sampled prepared at $a>100 \mathrm{~g}$, were cut into pieces and characterized by chemical analysis and XRD. Below, we will present the results obtained for the following two MMCs:

$$
\begin{array}{lll}
(1-\alpha) \mathrm{Mo}_{2} \mathrm{NiB}_{2}-\alpha \mathrm{Ni} & (\alpha=0.21) & \text { MMC I } \\
(1-\beta) \mathrm{Mo}_{2} \mathrm{FeB}_{2}-\beta \mathrm{Fe} & (\beta=0.25) & \text { MMC II }
\end{array}
$$

The above compositions seem most promising for practical implementation as a hardfacing material. In this work, we focused on the synthesis of the compositions enumerated in Table 3.

\subsubsection{I-Ni-58Mo-6B}

The results of chemical analysis are presented in Table 3 . The amounts of Mo and $\mathrm{Ni}$ are close to nominal values. The B content is slightly lower (by $0.2 \%$ ) probably due to occurrence of redox reactions with metal oxides competing for Al. This also explains the presence of $\mathrm{Al}(\sim 1$

\begin{tabular}{|c|c|c|c|c|c|c|}
\hline \multicolumn{7}{|c|}{ Nominal (wt\%) I Ni-58Mo-6B } \\
\hline \multicolumn{7}{|c|}{ Actual $(w t \%)$} \\
\hline $\mathrm{Ni}$ & Mo & $\mathrm{Fe}$ & B & $\mathrm{Al}$ & $\mathrm{Cr}$ & $\mathrm{V}$ \\
\hline bal. & 57.8 & - & 5.8 & 1.0 & - & - \\
\hline \multicolumn{7}{|c|}{ Nominal (wt \%) II Fe-49Mo-6B-2.5Cr-2.5V } \\
\hline \multicolumn{7}{|c|}{ Actual (wt $\%)$} \\
\hline- & 49.1 & bal. & 5.8 & 0.8 & 2.3 & 2.5 \\
\hline
\end{tabular}

Table 3. Nominal and actual composition of MMCs I and II.

$\mathrm{wt} \%$ ) in the resultant ingots.

The XRD and SEM data in Figure 15 suggest that the cast MMC $\mathbf{I}$ is formed by orthorhombic $\mathrm{Mo}_{2} \mathrm{NiB}_{2}$ and intermetallic compound $\mathrm{MoNi}_{4}$ with insignificant admixture of the MoNi phase. The material has a clearly pronounced composite structure. Detailed SEM/EDX element distribution analysis has confirmed (Figure 15(b)) that the material of matrix is largely Ni filled with $\mathrm{Mo}_{2} \mathrm{NiB}_{2}$ particles $20-30 \mu \mathrm{m}$ in their size uniformly distributed over the volume of cast material. The Al-rich areas were found to coincide with the Ni-rich ones.

\subsection{3. МMC II-Fe-49Mo-6B-2.5Cr-2.5V}

Figure 16 characterizes the phase composition and microstructure of MMC II. Here dark areas correspond to a matrix material while the brighter one, to hard filler. Comparative analysis of the XRD data (Figure 16(a)) and SEM/EDX element distribution images (Figure 16(b)) clearly shows that the material has a Fe matrix impregnated with $\mathrm{Cr}$ and $\mathrm{Ni}$ in the form of sold solutions $\left(\mathrm{F}_{\mathrm{ss}}\right)$. The boride $\mathrm{Mo}_{2} \mathrm{FeB}_{2}$ acts as a filler. Its particles about $10 \mu \mathrm{m}$ in size are uniformly distributed all over the volume of cast material. The alloying agents, $\mathrm{Cr}$ and $\mathrm{Ni}$, are distributed largely in a metal matrix and tabular eutectic deposits. Again, the Al-rich areas were found to coincide with the matrix ones (Fe and Ni-rich areas).

\subsubsection{Microstructure of Etched MMC I}

In order to make microstructures visible and clearly pronounced, prior to analysis all metallographic specimens were subjected to short-term acid etching to partially remove $\mathrm{Ni}(\mathrm{Fe})$-based matrices. The results obtained for MMC I are presented in Figure 17. The microstructure of polished surface after etching reveals a two-storey architecture.

The first level (Figure 17(a)) is formed by a metal/ceramic structure in which dark-gray areas are formed by $\mathrm{Ni}_{4} \mathrm{Mo}$ in which distributed are the boride $\mathrm{Mo}_{2} \mathrm{FeB}_{2}$ particles with a size of $10-20 \mu \mathrm{m}$ (bright-gray areas).

This is a basic structural element of synthesized MMCs. At higher magnification (Figures 17(b) and (c)) we can also discern the spatially strengthening body- 


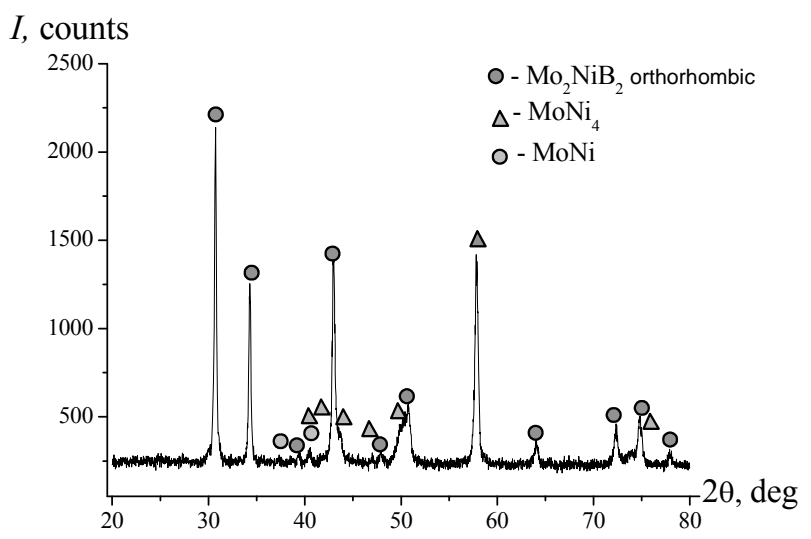

(a)
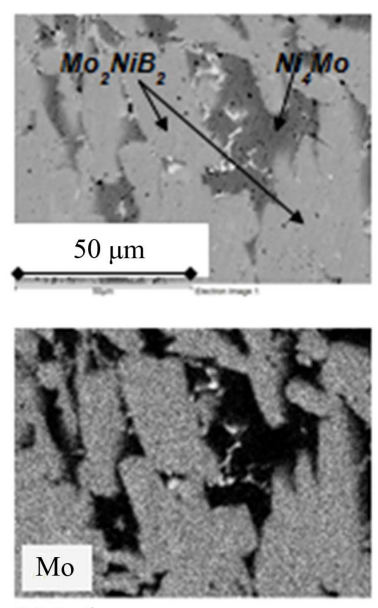

MoLa1

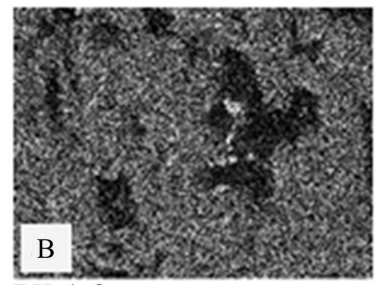

BKa1_2
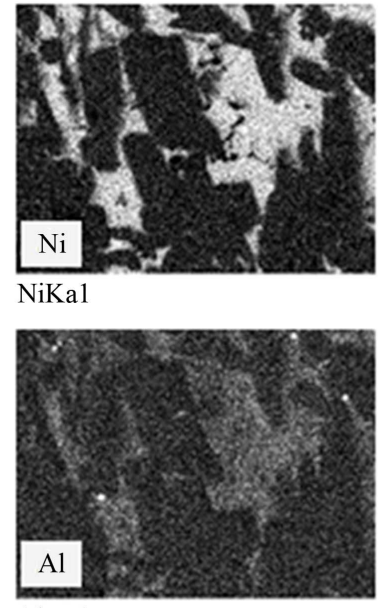

(b)

Figure 15. Diffraction pattern (a) and SEM EDX element distribution images (b) in MMC I (nominal composition Ni-58Mo-6B).

structured units of the metal matrix. The second storey is formed by intermetallic/intermetallic elements. After removal of $\mathrm{Ni}_{4} \mathrm{Mo}$, we could discern the nanosized deposits of a grid-type structure with a cell size of 100 $120 \mathrm{~nm}$. According to EDS data, composition of these deposits is close to $\mathrm{Ni}(\mathrm{Mo})_{3} \mathrm{Al}$.

The presence of $\mathrm{Al}$ can be associated with incomplete reduction of molybdenum and nickel oxides. As a result, excessive $\mathrm{Al}$ is formed, which leads to formation of aluminides at the stage of crystallization. Since lower aluminides are acid-resistant, they could not be eliminated by etching. Apparently, the above mentioned grid-like

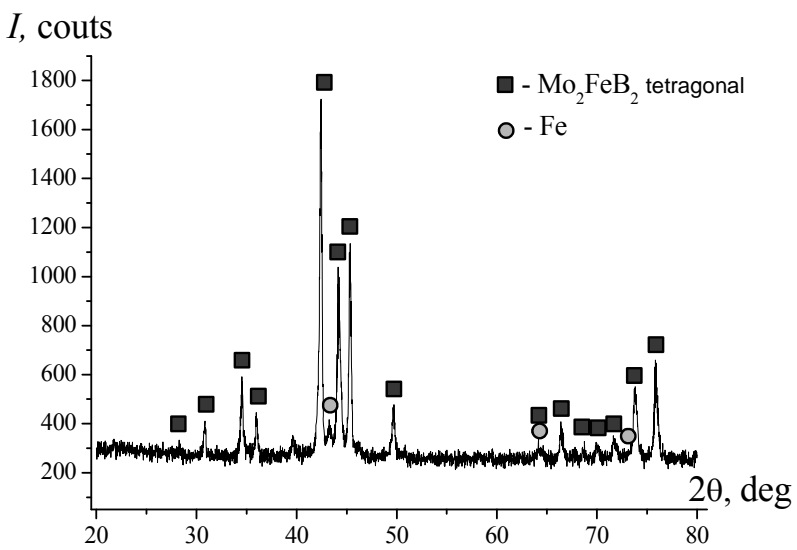

(a)
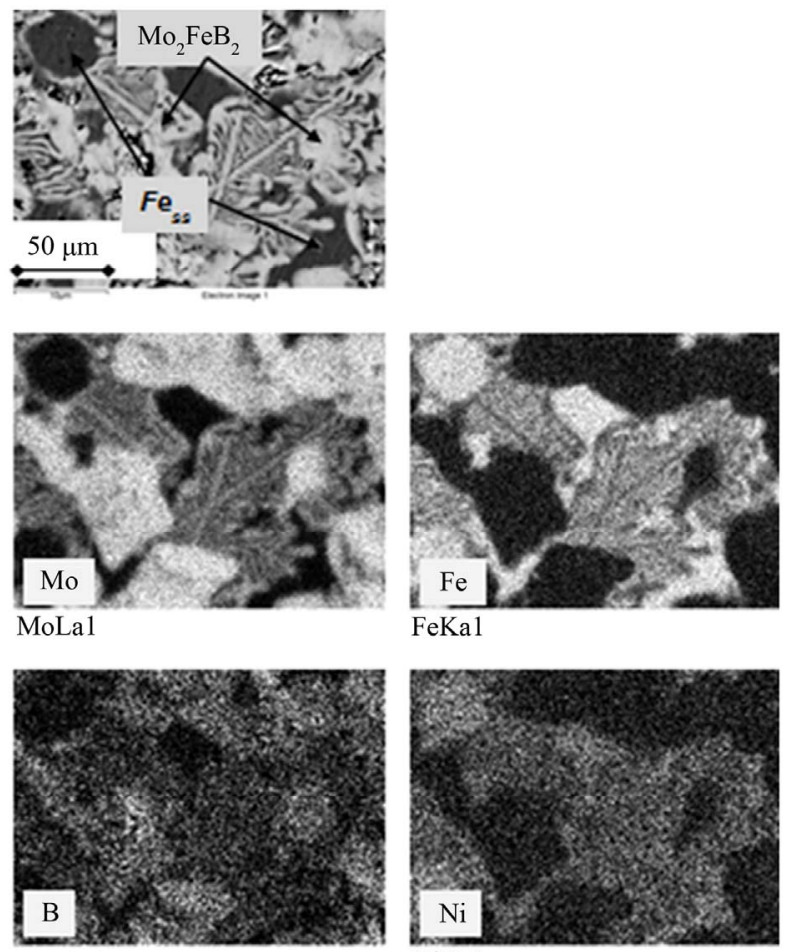

BKal_2
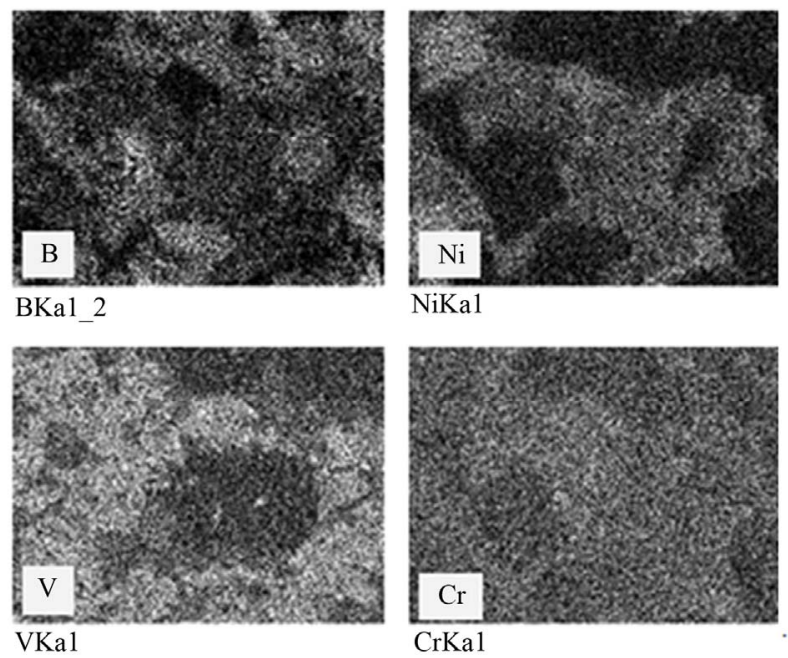

(b)

Figure 16. Diffraction pattern (a) and SEM EDX element distribution images (b) in MMC II (nominal composition Fe-49Mo-6B-2.5Cr-2.5V).

structure is formed at the boundaries between $\mathrm{Ni}_{4} \mathrm{Mo}$ and NiMo grains.

Note that synthesized samples have not been subjected 


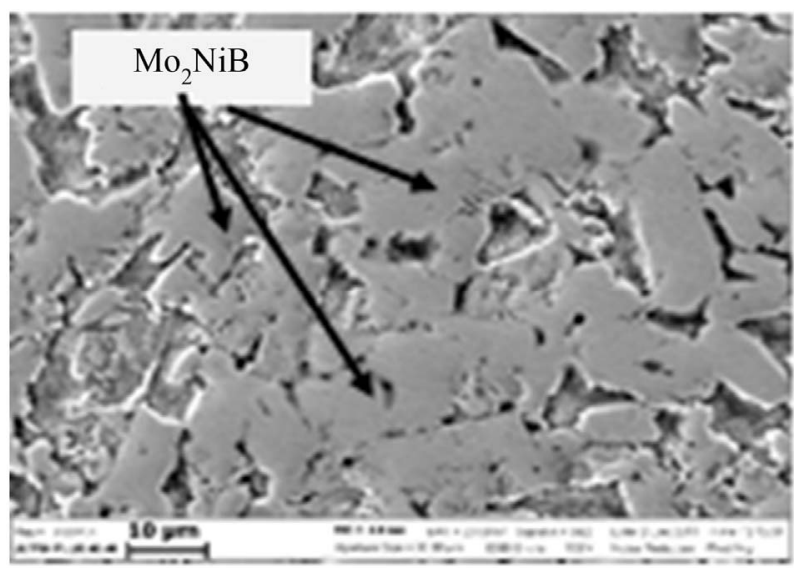

(a)

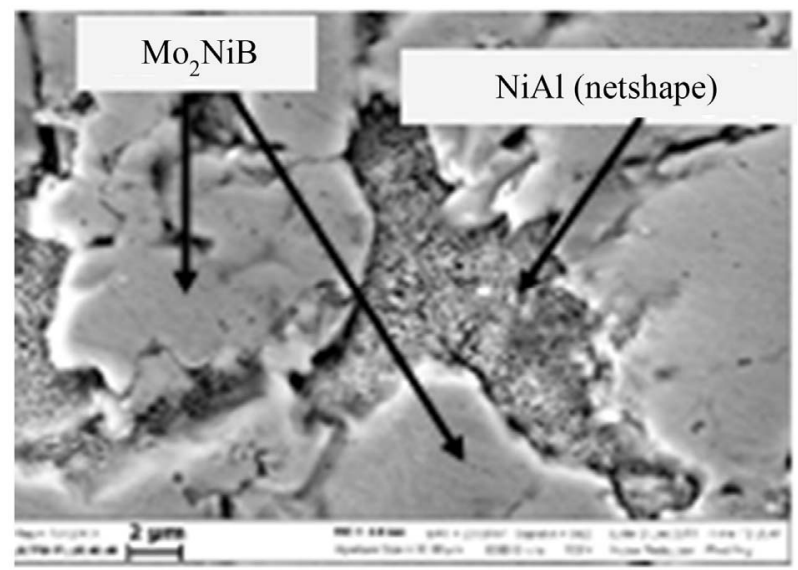

(b)

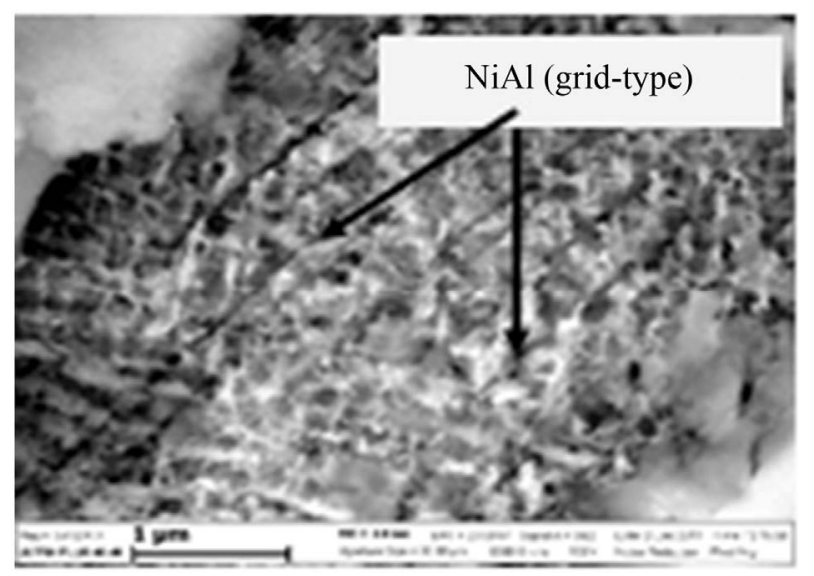

(c)

Figure 17. SEM micrograph of MMC I-Ni-58Mo-6B composite (polished surface after etching).

to an additional thermal treatment; the pattern formation took place during the SHS process (in situ).

\subsubsection{Effect of Alloying Agents and Hardness Results}

The influence of alloying agents (AAs) on the composition/morphology of complex borides was explored by
Takagi et al. [30-33,38]. In this work, we attempted to introduce AAs (such as $\mathrm{Cr}_{2} \mathrm{O}_{3}, \mathrm{~V}_{2} \mathrm{O}_{5}, \mathrm{MnO}_{2}$ ) into green mixtures, prior to combustion synthesis. Nominally, the AA content of MMCs might not exceed $5 \mathrm{wt} \%$. First results showed that the addition of AAs strongly affects the composition/morphology of $\mathrm{Mo}_{2} \mathrm{NiB}_{2}$ - containing MMCs. It follows that the addition $\mathrm{Cr}$ and $\mathrm{V}$ changes a structural type of boride cell from the orthorhombic to tetragonal one.

The results of hardness testing of MMCs with addition different AAs are collected in Table 4. The hardness of synthesized MMCs is rather high and attains as large value as $1200 H_{\mathrm{V}}$. The highest hardness is exhibited by MMCs alloyed with $\mathrm{Cr}$ and V. Apparently this can be related to some change in a type of the structural cell of borides. The indenter imprints did not show any visible cracking around them. This can be regarded as evidence for a proper choice of optimal relationships between the volume fractions of metal matrix and strengthening boride particles.

\section{Conclusions}

The obtained cast multi-component intermetallic alloys by combined centrifugal casting - SHS process can promote a decline an operation time of vacuum furnace and simplify existing commercial technology of their preparing. Synthesized cast alloys can find their potential application as heat-resistant materials, master alloys, precursors for catalysts, etc.

The main advantages of the SHS technology include low energy costs, higher productivity (due to the smalltime synthesis), the use of cheaper raw materials (metal oxides) and the use of cheaper equipment. Realization of high temperatures without using any additional power sources gives main competitive advantage from the conventional vacuum electrometallurgy. The composition/ structure of SHS-produced cast multicomponent alloys in centrifuges was found strongly dependent on the extent of centrifugal overload $a / \mathrm{g}$. created in the centrifugal SHS installations.

Cast $\mathrm{Mo}_{2} \mathrm{NiB}_{2}$ and $\mathrm{Mo}_{2} \mathrm{FeB}_{2}$ based metal-matrix composites (MMCs) with good service parameters were prepared for the first time by combined centrifugal casting -SHS process. The composite structure of synthesized

Table 4. Results of hardness tests.

\begin{tabular}{ccc}
\hline MMC (wt\%) & $H_{\mathrm{V}}$ & HRA \\
\hline Ni-58Mo-6B & 1060 & 82 \\
Ni-58Mo-6B-5Cr & 1170 & $83-84$ \\
Ni-58Mo-6B-5V & 1200 & $84-85$ \\
Ni-58Mo-6B-3Mn & 980 & 81 \\
\hline
\end{tabular}


MMCs was formed in situ SHS process. The materials and process can be recommended for practical implementation in production of cutting tools, tribological materials, moulds, and deposition of protective coatings. The present results can be expected to make a theoretical background for industrial-scale manufacturing of new tungsten-free MMCs with valued properties.

\section{Acknowledgements}

The work was supported by the Russian Foundation for Basic Research (project no. 12-03-00637) and Governmental Program on support of Russian research and educational personnel in the years of 2009-2013 (contract no. 14.132.21.1595).

\section{REFERENCES}

[1] C. T. Sims, N. S. Stoloff and W. C. Hagel, "Superalloys II,” John Wiley \& Sons, New York, 1987.

[2] R. D. Noebe, R. R. Bowman and M. V. Nathal, "Physical Metallurgy and Processing of Intermetallic Compounds," Chapman \& Hall, New York, 1996, pp. 212-296. doi:10.1007/978-1-4613-1215-4 7

[3] G. Frommeyer and R. Rablbauer, "High Temperature Materials Based on the Intermetallic Compound $\mathrm{NiAl}$ Reinforced by Refractory Metals for Advanced Energy Conversion Technologies, Materials Technology," Steel Research International, Vol. 79, No. 7, 2008, pp. 507512.

[4] S. Rawal, "Metal-Matrix Composites for Space Applications," JOM, Vol. 53, No. 4, 2001, pp. 14-17. doi:10.1007/s11837-001-0139-z

[5] J. Baetz, "Metal Matrix Composites: Their Time Has Come," Aerospace America, 1998, pp. 14-16.

[6] S. T. Mileiko, A. V. Serebryakov, V. M. Kiiko, A. A. Kolchin, V. N. Kurlov and N. I. Novokhatskaya, "Single Crystalline Mullite Fibres Obtained by the Internal Crystallisation Method: Microstructure and Creep Resistance," Journal of the European Ceramic Society, Vol. 29, No. 3, 2009, pp. 337-345.

[7] A. J. Smith, L. O. Garciano, T. Tam and M. S. Wainwright, "Structure and Kinetics of Leaching for the Formation of Skeletal (Raney) Catalysts," Industrial \& Engineering Chemistry Research, Vol. 47, No. 5, 2008, pp. 1409-1415. doi:10.1021/ie 070801b

[8] B. W. Hoffer, E. Crezee, F. Devred, P. R. M. Mooijman, W. G. Sloof, P. J. Kooyman, A. D. van Langeveld, F. Kapteijn and J. A. Moulijn, "The Role of the Active Phase of Raney-Type Ni Catalysts in the Selective Hydrogenation of d-Glucose to d-Sorbitol," Applied Catalysis A: General, Vol. 253, No. 2, 2003, pp. 437-452. doi:10.1016/S0926-860X(03)00553-2

[9] A. G. Merzhanov and S. Yu. Sharivker, "Self-Propagating High-Temperature Synthesis of Carbides, Nitrides, and Borides," In: Y. G. Gogotsi and R. A. Andrievski, Eds., Materials Science of Carbides, Nitrides, and Borides, Kluwer Academic Publishers, Dordrecht, 1999, pp.
205-222. doi:10.1007/978-94-011-4562-6 12

[10] N. P. Lyakishev, Yu. L. Pliner, G. F. Ignatenko and S. I. Lappo, "Alyuminotermiya (Aluminothermy)," Metallurgiya, Moscow, 1978, $421 \mathrm{p}$.

[11] V. I. Yukhvid, G. A. Vishnyakova, S. L. Silyakov, V. N. Sanin and A. R. Kachin, "Structural Macrokinetics of Alumothermic SHS Processes," International Journal of Self-Propagating High-Temperature, Vol. 5, No. 1, 1996, pp. 93-105.

[12] A. G. Merzhanov, "SHS Technology," Advanced Materials, Vol. 4, No. 4, 1992, pp. 294-295.

[13] V. I. Yukhvid, "Effect of Convective Motion on the Flame Structure in Combustion Waves Propagating in Heterogeneous Systems under Natural and Artificial Gravity Conditions," Combustion, Explosion, and Shock Waves, 2009, Vol. 45, No. 4, pp. 421-427. doi:10.1007/s10573-009-0052-2

[14] V. I. Yukhvid, V. N. Sanin and A. G. Merzhanov, "The Influence of High Artificial Gravity on SHS Processes. Processing by Centrifugation," Kluwer Academic, Dordrecht, 2001, p. 185. doi:10.1007/978-1-4615-0687-4_26

[15] V. N. Sanin and V. I. Yukhvid, "Effect of Artificial Gravity on SHS Foam Materials Based on Ti-C," Journal of Materials Processing and Manufacturing Science, Vol. 7, No. 1, 1998, pp. 115-125.

[16] V. N. Sanin and V. I. Yukhvid, "Infiltration of the Melt under the Influence of Centrifugal Force in High-Temperature Layered Systems," Inorganic Materials, Vol. 41, No. 2, 2005, pp. 1-9.

[17] V. N. Borshch, E. V. Pugacheva, S. Ya. Zhuk, et al., "Multi-Component Metallic Catalysts for Deep Oxidation of Carbon Monoxide and Hydrocarbons," Doklady Akademii Nauk, Vol. 419, No. 6, 2008, pp. 775-777.

[18] Y. W. Kim and F. H. Foes, "Physical Metallurgy of Titanium Aluminides: Microstructure/Property Relationships in Titanium Alloys and Titanium Aluminides," In: S. H. Wang, Ed., High Temperature Aluminides and Intermetallics, TMS, Warrendale, 1990, p. 4496.

[19] "Materials Properties Handbook: Titanium Alloys," ASM International, 1994.

[20] J. Davies, A. Nozue, S. Nakabayashi and T. Okubo, "Fracture Behaviour of Boride-Dispersed Composites Fabricated by Hot-Pressing Amorphous Ni60Mo30B10 Powder," Journal of Materials Science, Vol. 33, No. 19, 1998, pp. 4727-4732. doi:10.1023/A:1004441205253

[21] L. L. Wang, B. W. Zhang, G. Yi, Y. F. Ouyang and W. Y. $\mathrm{Hu}$, "Structure and Crystallization of Amorphous Fe-MoB Alloys Obtained by Electroless Plating," Journal of Alloys and Compounds, Vol. 255, No. 1-2, 1997, pp. 231235. doi:10.1016/S0925-8388(96)02843-5

[22] K.-I. Takagi, "Development and Application of High Strength Ternary Boride Base Cermets," Journal of Solid State Chemistry, Vol. 179, No. 9, 2006, pp. 2809-2818. doi:10.1016/j.jssc.2006.01.023

[23] Y. Yamasaki, M. Nishi and K.-I. Takagi, "Development of Very High Strength $\mathrm{Mo}_{2} \mathrm{NiB}_{2}$ Complex Boride Base Hard Alloy," Journal of Solid State Chemistry, Vol. 177, No. 2, 2004, pp. 551-555doi:10.1016/j.jssc.2003.03.008 
[24] K.-I. Takagi and Y. Yamasaki, "Effects of Mo/B Atomic Ratio on the Mechanical Properties and Structure of $\mathrm{Mo}_{2} \mathrm{NiB}_{2}$ Boride Base Cermets with $\mathrm{Cr}$ and V Additions," Journal of Solid State Chemistry, Vol. 154, No. 1, 2000, pp. 263-268.

[25] K.-I. Takagi, "High Tough Boride Base Cermets Produced by Reaction Sintering," Materials Chemistry and Physics, Vol. 67, No. 1-3, 2001, pp. 214-219.

[26] X. M. Pang, Y. Zheng, S. G. Wang and Q. H. Wang, "Effect of Mn on Valence-Electron Structure and Properties of Hard Phase in $\mathrm{Mo}_{2} \mathrm{FeB}_{2}$-Based Cermets," International Journal of Refractory Metals and Hard Materials, Vol. 27, No. 4, 2009, pp. 777-780. doi:10.1016/j.ijrmhm.2009.01.004

[27] Y. Shiota, Y. Miyajima, T. Fujima and K.-I. Takagi, "Effect of Double Addition of $\mathrm{V}$ and $\mathrm{Cr}$ on the Properties of $\mathrm{Mo}_{2} \mathrm{NiB}_{2}$ Ternary Boride-Based Cermets," Journal of Physics: Conference Series, Vol. 176, No. 1, 2009, Article ID: 012046.
[28] B. Yuan, G.-J. Zhang, Y.-M. Kan and P.-L. Wang, "Reactive Synthesis and Mechanical Properties of $\mathrm{Mo}_{2} \mathrm{NiB}_{2}$ Based Hard Alloy," International Journal of Refractory Metals and Hard Materials, Vol. 28, 2010, pp. 291- 296. doi:10.1016/j.ijrmhm.2009.11.002

[29] H. Z. Yu, Y. Zheng, W. J. Liu, X. M. Pang, J. Z. Zheng and W. H. Xiong, "Effect of Mo/B Atomic Ratio on the Microstructure and Mechanical Properties of $\mathrm{Mo}_{2} \mathrm{FeB}_{2}$ Based Cermets," International Journal of Refractory Metals and Hard Materials, Vol. 28, 2010, pp. 338-342. doi:10.1016/j.ijrmhm.2009.11.008

[30] H. Z. Yu, W. J. Liu and Y. Zheng, "Microstructure and Mechanical Properties of Liquid Phase Sintered $\mathrm{Mo}_{2} \mathrm{FeB}_{2}$ Based Cermets," Materials and Design, Vol. 32, No. 6, 2011, pp. 3521-3525. doi:10.1016/j.matdes.2011.02.034

[31] V. Sanin, D. Andreev, D. Ikornikov and V. Yukhvid, "Cast Intermetallic Alloys by SHS Under High Gravity," Journal Acta Physica Polonica A, Vol. 120, No. 2. 2011, pp. 331-335. 